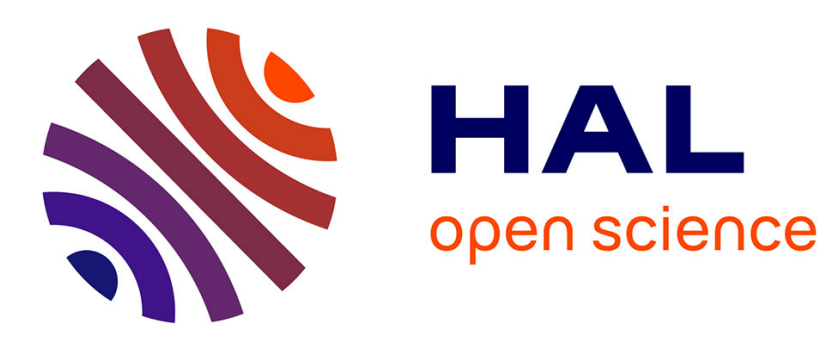

\title{
Design and irradiation test of an innovative optical ionization chamber technology
}

Maxime Lamotte, G. de Izarra, C. Jammes

\section{To cite this version:}

Maxime Lamotte, G. de Izarra, C. Jammes. Design and irradiation test of an innovative optical ionization chamber technology. Nuclear Instruments and Methods in Physics Research Section A: Accelerators, Spectrometers, Detectors and Associated Equipment, 2020, 968, pp.163945. 10.1016/j.nima.2020.163945 . cea-02932155

\section{HAL Id: cea-02932155 https://hal-cea.archives-ouvertes.fr/cea-02932155}

Submitted on 7 Sep 2020

HAL is a multi-disciplinary open access archive for the deposit and dissemination of scientific research documents, whether they are published or not. The documents may come from teaching and research institutions in France or abroad, or from public or private research centers.
L'archive ouverte pluridisciplinaire HAL, est destinée au dépôt et à la diffusion de documents scientifiques de niveau recherche, publiés ou non, émanant des établissements d'enseignement et de recherche français ou étrangers, des laboratoires publics ou privés. 


\title{
Design and irradiation test of an innovative optical ionization chamber technology
}

\author{
M. Lamotte ${ }^{\mathrm{a}}$, G. De Izarra ${ }^{\mathrm{a}}$, C. Jammes ${ }^{\mathrm{a}}$
}

${ }^{a}$ CEA, DEN DER, Instrumentation Sensors and Dosimetry Laboratory, Cadarache, F-13108 Saint-Paul-lez-Durance, France.

\begin{abstract}
To provide future dependable neutron flux monitoring instrumentation for sodiumcooled fast reactors (SFR) of Generation-IV, French Alternative Energies and Atomic Energy Commission (CEA) is investigating the applicability of an innovative technology based on the optical signal produced within any type of ionization chambers such as fission chambers for instance. A mock-up of that innovative neutron detector was tested on a cold-neutron beamline at the ORPHEE nuclear facility. Experimental results regarding recovery time and detection efficiency showed promising possibilities for neutron instrumentation.

Keywords: fission chambers, radiation-hard detectors, gaseous detectors, gas scintillation

PACS: 29.85.-cAMODIF, 28.50.Dr, 28.41.Rc
\end{abstract}

\section{1. Introduction}

2 The French Atomic and Alternative Energies Commission (CEA) proposes

3 a new generation of neutron detector for neutron flux monitoring of a sodium-

4 cooled fast reactor [1-5].This innovative neutron detector is based on the luminescence

5 of rare gases [6].

- As in any ionization chambers, heavy ions with high ionization power are generated

7 by a coating layer sensitive to neutrons. The slowing down of heavy ions in

s rare gas by inelastic collisions generates electrons with a continuous energy

- distribution ranging from rest up to several $\mathrm{keV}$. The average kinetic energy of

Preprint submitted to Nuclear Instrumentation and Methods section A.

March 31, 2020 

17 sounds doable.

primary electrons, about 30 to $50 \mathrm{eV}$ gives them a probability to bring gas atoms to excited states and produce further secondary electrons until recombinations, wall or thermal-equilibrium diffusion within the medium [7]. Spontaneous radiative decay of excited atoms rises emission of photons in the ultraviolet to far-infrared range $[8,9]$. The so-called radiation-induced-absorption (RIA) of silica optical fibers being minimal in the near-infrared spectrum [10], the transportation of the generated optical signal in the harsh environment of a nuclear power plant

Compared to standard ionization chambers and proportional counters, the proposed optical version of neutron gaseous detectors allow for enhanced on-line selfdiagnosis in terms of working pressure and gas composition [11], increasing the detector and nuclear reactor dependability thanks to better preventive maintenance capabilities. In addition, optical ionization chambers are neither affected by partial discharge effects at high temperature nor electromagnetic noise thanks to optical signal transmission.

This paper addresses the experimental validation of the CANOE mock-up of an optical ionization chamber in order to bring a proof of concept of the newly proposed technology. It starts with the design of the CANOE mock-up. The measurement setup of the optical signal transmission and detection is then presented. At last, the experimental results obtained at the ORPHEE nuclear facility are reported and discussed.

\section{Optical ionization chamber mock-ups}

An optical fission chamber mock-up, named CANOE (CApteur de Neutrons à Optique Expérimentale), was designed and built at the French Alternative Energies and Atomic Energy Commission (CEA). The purpose of this mockup is to perform preliminary experimental tests for the sake of technology development only. This way, at the present phase of our project, it is not defined to endure the harsh environment of an SFR.

Its main component is an aluminum-alloy-based tube filled with a rare gas 
39

43 a computer-aided cutaway of a CANOE detector, the sensitive component of 44 which is a boron-coated tube. Tab.1 provides some information on the three 45 different layers that we employed at the ORPHEE facility (§3.3) such as the

46 heavy-ion energy deposition rate $\Delta E$.

47 The cylindrical chamber body is closed by a $10 \mathrm{~mm}$-thick molten-silica window

${ }_{54}$ In addition, a polished pure rhodium disk was placed at the other end, opposite

55 to the window, so that it helps to reflect photons escaping in the unwanted

56 direction.

57

\section{3. Instrumentation and experimental setup}

59 We seized the last opportunity to carry out a partial experimental validation 60 of the CANOE mock-up at the ORPHEE nuclear facility before its closure at 61 the end of the year 2019.

62 3.1. Selection of optical fibers

${ }_{63}$ We had two available types of multi-mode optical fibers. The first one is ${ }_{64}$ a $20 \mathrm{~m}$-long industrial-grade fiber ended by SMA connectors, and featuring a $65200 \mu \mathrm{m}$-diameter pure silica core and 0.2 Numerical Aperture (NA). The second

${ }_{66}$ fiber type is composed of a $980 \mu \mathrm{m}$-diameter core made of PMMA (polymethyl 
(a) Computer-aided cutaway

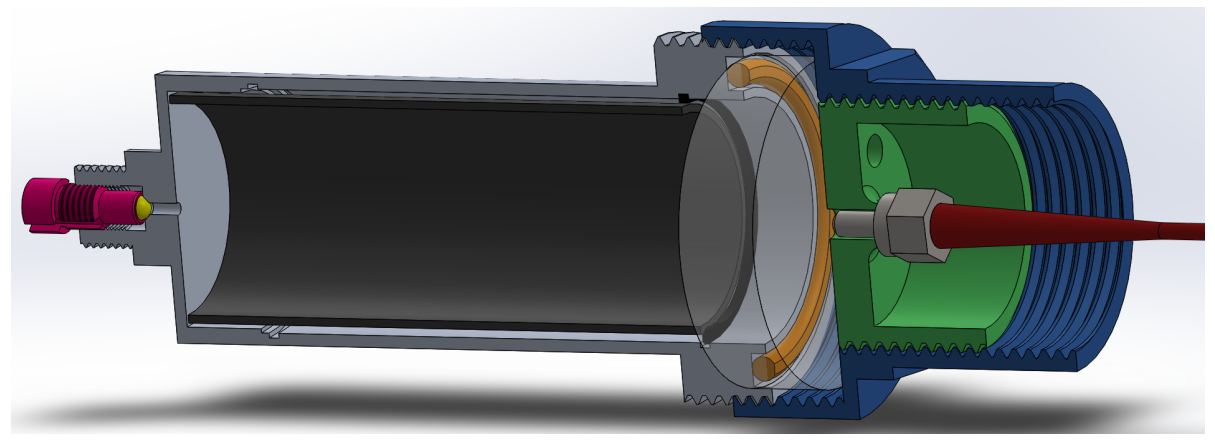

(b) Photography

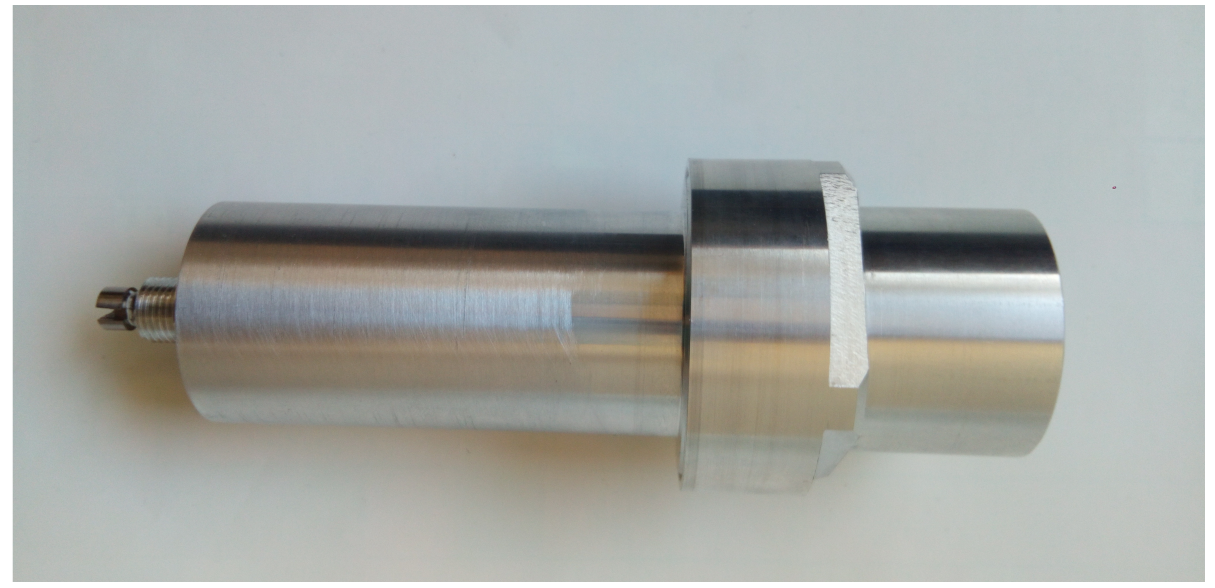

Figure 1: CANOE mock-up. of CANOE. The neutron sensitive layer is enriched a boron carbide, coupled with a $200 \mu \mathrm{m}$-diameter core silica fiber, with no use of focusing assembly. 


\begin{tabular}{rcccccc}
\hline Material & $\mathrm{E}_{0}(\mathrm{MeV})$ & $\mathrm{M}(\mathrm{mg})$ & $\mathrm{T}(\mathrm{um})$ & $\mathrm{S}\left(\mathrm{cm}^{2}\right)$ & $\sigma(\mathrm{b})$ & $\Delta E(\mathrm{MeV} / \mathrm{s})$ \\
\hline${ }^{235} \mathrm{U}_{3} \mathrm{O}_{8}$ & 167 & 0.75 & 0.51 & 1.76 & 1627 & $1.75 \mathrm{E} 8$ \\
${ }^{10} \mathrm{~B}_{4} \mathrm{C}$ & 2.31 & 30 & 2.0 & 61.5 & 10335 & $1.33 \mathrm{E} 10$ \\
${ }^{238} \mathrm{PuO}_{2}$ & 5.5 & 1.8 & 0.88 & 1.76 & $\mathrm{NA}$ & $2.95 \mathrm{E} 9$ \\
\hline
\end{tabular}

Table 1: Various sensitive layers for CANOE mock-ups. $\mathrm{E}_{0}(\mathrm{MeV})$ : initial kinetic energy of heavy-ions produced by spontaneous decay or neutron-induced reactions. Surface S: that of ion emission coating of mass $\mathrm{M}$ and thickness $\mathrm{T}$.,$\sigma$ : neutron-reaction cross-section at $3.5 \mathrm{meV}$ for fission $\left({ }^{235} \mathrm{U}\right)$ and alpha particle $\left({ }^{10} \mathrm{~B}\right)$ production. $\Delta E$ : energy deposition rate within the gas for a neutron flux of $8 \mathrm{E} 8 \mathrm{~cm}^{-2} \cdot \mathrm{s}^{-1}$ if $50 \%$ of the ions reach the gas with an energy $\mathrm{E}_{0}$. Being an alpha-particle emitter, ${ }^{238} \mathrm{PuO}_{2}$ played the role of a calibration source, the energy deposition rate of which is that of alpha particles.

67 methacrylate), displaying a NA of 0.5 , being able to be cut at wanted length (a

$683.5 \mathrm{~m}$-length was actually required). That plastic-made optical fiber, while being

69 unfitted to high neutron fluences and temperatures of an SFR, exhibits neither

7o scintillation nor radiation-induced-absorption in the gamma-particle field met

71 on the cold-neutron beamlines of the ORPHEE facility. Its wider core diameter

72 makes it possible to significantly increase the collected light intensity. As a

73 result, that fiber was selected.

74 3.2. Multiple light sensor technologies

75 Two technologies of light sensors were assessed. Fig. 2 presents the experimental 76 setup used for CANOE evaluation: silicon photomultipler ( $\mathrm{SiPM}$ ) and Geiger77 mode avalanche photodiode (APD) were selected for their very good timing 78 performance (recovery time of about a few tens of nanosecond) and high photon79 to-electron conversion efficiency (above $15 \%$ at $600 \mathrm{~nm}$ ). The available large so active areas of SiPM allow for light detection from uncollimated light pipes, s1 pulse height analysis and fast recovery time. However, they require a cooling 82 system to reduce dark noise signals.

83 A Ketek evaluation board embedding a WB-1125 SiPM of $1 \times 1 \mathrm{~mm}^{2}$ area was 
84 coupled to a low-noise high-frequency monolithic dual stage amplifier consisting

85 of MAR-3 and MAR-4 chips enabling 12 and $8 \mathrm{~dB}$ amplification at $1 \mathrm{GHz}$,

s6 respectively. The SiPM sensor was polarized with an over-voltage of $3 \mathrm{~V}$, at

${ }_{87}$ room temperature $\left(22^{\circ} \mathrm{C}\right)$ and kept in an aluminium case to prevent electromagnetic

8 perturbation. The optical fibre was directly coupled through the air to the SiPM

89 active area.

9o A Geiger-mode APD was a Peltier-cooled Hamamatsu C13001-01 module offering

91 on-board temperature regulation, pulse discrimination, signal amplification and

92 TTL output of $10-n s$ width. Discrimination threshold is manufacturer-fixed.

93 The coupling to the APD sensor is ensured by a standard FC optical connector.

94 Adapters between the bare or SMA-terminated fibers and a CANOE mock-

95 up were manufactured with a $3 \mathrm{D}$ printer. They were then wrapped with an

96 aluminum ribbon for efficient light-tightness.

97 Table 2 sums up the most important specification of the employed light sensors

98 at the ORPHEE facility.

\begin{tabular}{rrrrrrr}
\hline Sensor & DN (cps) & $\tau(n s)$ & $\mathrm{T}\left({ }^{\circ} \mathrm{C}\right)$ & $\mathrm{S}\left(\mathrm{mm}^{2}\right)$ & $\mathrm{PDE} 1(\%)$ & PDE2(\%) \\
\hline SiPM WB-1125 & $65 \mathrm{E} 3$ & 30 & 22 & 1.00 & 32 & 2.3 \\
APD C13001 & 17 & 10 & -20 & $1 \mathrm{E}-4$ & 20 & 2.1 \\
\hline
\end{tabular}

Table 2: Main specifications of light sensors used with CANOE mock-ups. DN stands for Dark Noise (without fiber). $\tau$ denotes the recovery time, $\mathrm{T}$ the substrate temperature and $\mathrm{S}$ its surface. PDE 1 and 2 are photon-detection efficiencies at $585 \mathrm{~nm}$ and $849 \mathrm{~nm}$, respectively.

\subsection{Setup at ORPHEE}

As shown in Fig. 3, the CANOE experimental test was performed on the G3-2 beamline of the ORPHEE facility dedicated to neutron diffusion and diffraction experiments. The neutron source is provided by a 14 MW highly enriched uranium-235 pool-type reactor in operation since 1980. The latter is 


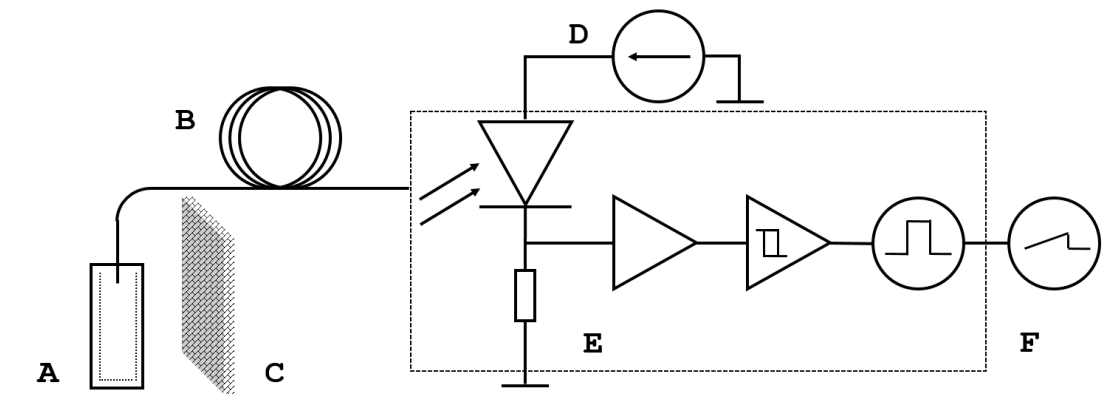

Figure 2: Experimental setup for neutron sensitivity testing of CANOE mock-ups. A: CANOE, B: optical fiber, C: lead shield, D: fixed voltage power supply, E: SiPM or APD signal shaping board, F: oscilloscope .

equipped with 9 horizontal tubes, tangential to the core, allowing the use of 20 neutron beams. The common end of those tubes is located in the moderator near the core, where the flux of thermalized neutrons is maximum. The G3-2 cold neutron beamline of a $25 \times 50 \mathrm{~mm}^{2}$ section provides a mono-directional flux as low as $8 \mathrm{E} 8 \mathrm{n} . \mathrm{cm}^{-2} . \mathrm{s}^{-1}$ with an average neutron energy of about $3.5 \mathrm{meV}$. A boron-coated pneumatic-driven shutter, also referred as to flipper, of about $20 \mathrm{~cm}$ high is able to stop the neutron beam within 100 milliseconds. The light sensors are placed in a lead-shielded casemate [12, 13]. Opening and closing that casemate is performed manually by pushing a sliding lead door, giving so an easy access and work-time efficiency.

Because of the low neutron flux available, we had to fill the CANOE mock-ups with high-purity neon. This way, the emission spectrum was shifted towards visible wavelengths. Unlike argon, neon at the same pressure enhanced the detection efficiency of the chosen light sensors as well. For instance, the APD detection efficiency was significantly improved from $2 \%$ at $912 \mathrm{~nm}$ with argon to $32 \%$ at $585 \mathrm{~nm}$ generated with neon (Fig. 4). Overall, a CANOE mockup loaded with $1.8 \mathrm{mg}{ }^{238} \mathrm{Pu}$, dedicated to calibration as already mentioned, permitted to obtain up to $4700 \mathrm{cps}$ when filled with neon at $2 \mathrm{~atm}$, whereas argon at the same pressure led to 72 cps only. 


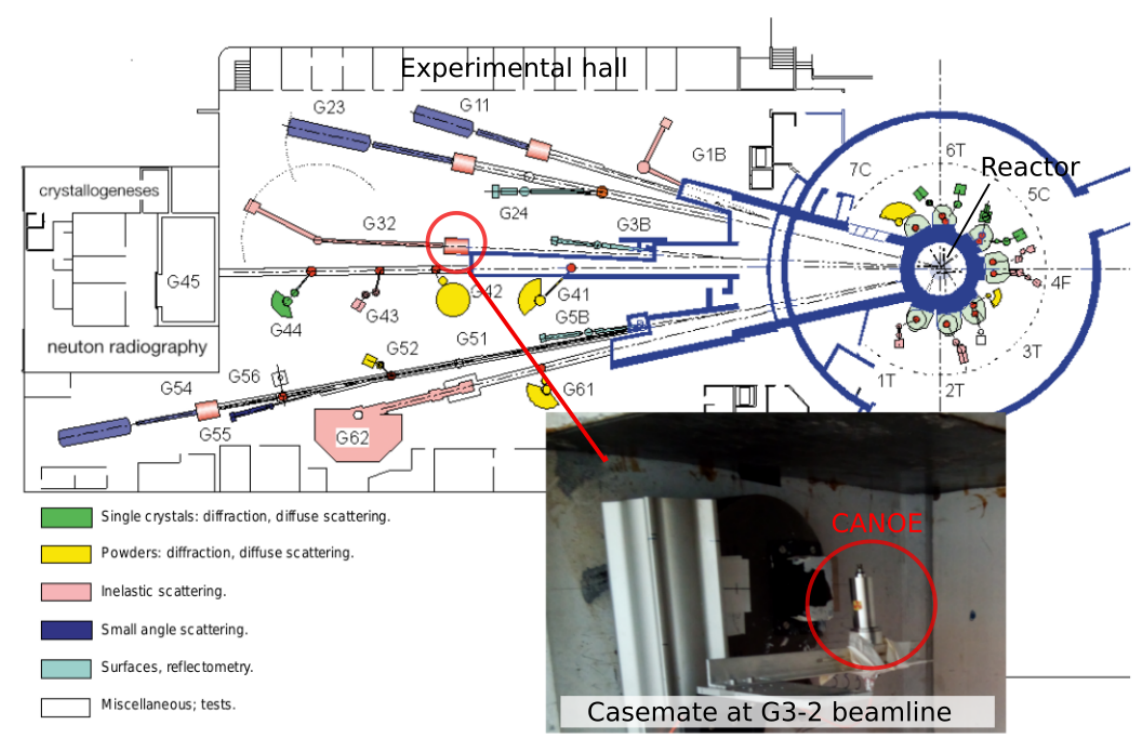

Figure 3: Experimental setup at ORPHEE. The G3-2 cold neutron beamline of a $25 \mathrm{x} 50 \mathrm{~mm}^{2}$ section provides a mono-directional flux as low as $8 \mathrm{E} 8 \mathrm{n} . \mathrm{cm}^{-2} \cdot \mathrm{s}^{-1}$.

\section{Results and discussion}

We started to estimate the dark noise signal of the two light sensors,namely the APD and SiPM ones, by performing an acquisition without CANOE or fibers. Their active area was covered with a thick fabrics and aluminum foils while counts were recorded over several minutes to reduce statistical uncertainties. A count rate ranging between 19 and 25 cps was obtained with APD, whereas SiPM generated $65,000 \mathrm{cps}$ with a threshold set to $1 \mathrm{PE}$ (photo-electron), the smallest pulse height achievable, to gather all other pulses of higher intensities both induced by dark-noise and useful signal.

The unavoidable ambient light at the irradiation location is likely to penetrate the general-purpose unsheathed optical fibers and come to bias the signal. In order to limit that bias, the fibers went through a PVC tube. CANOE was then placed for several minutes into the casemate without neutrons. As the pulse rate did not increase, the light-tightness of the experimental setup was checked. 


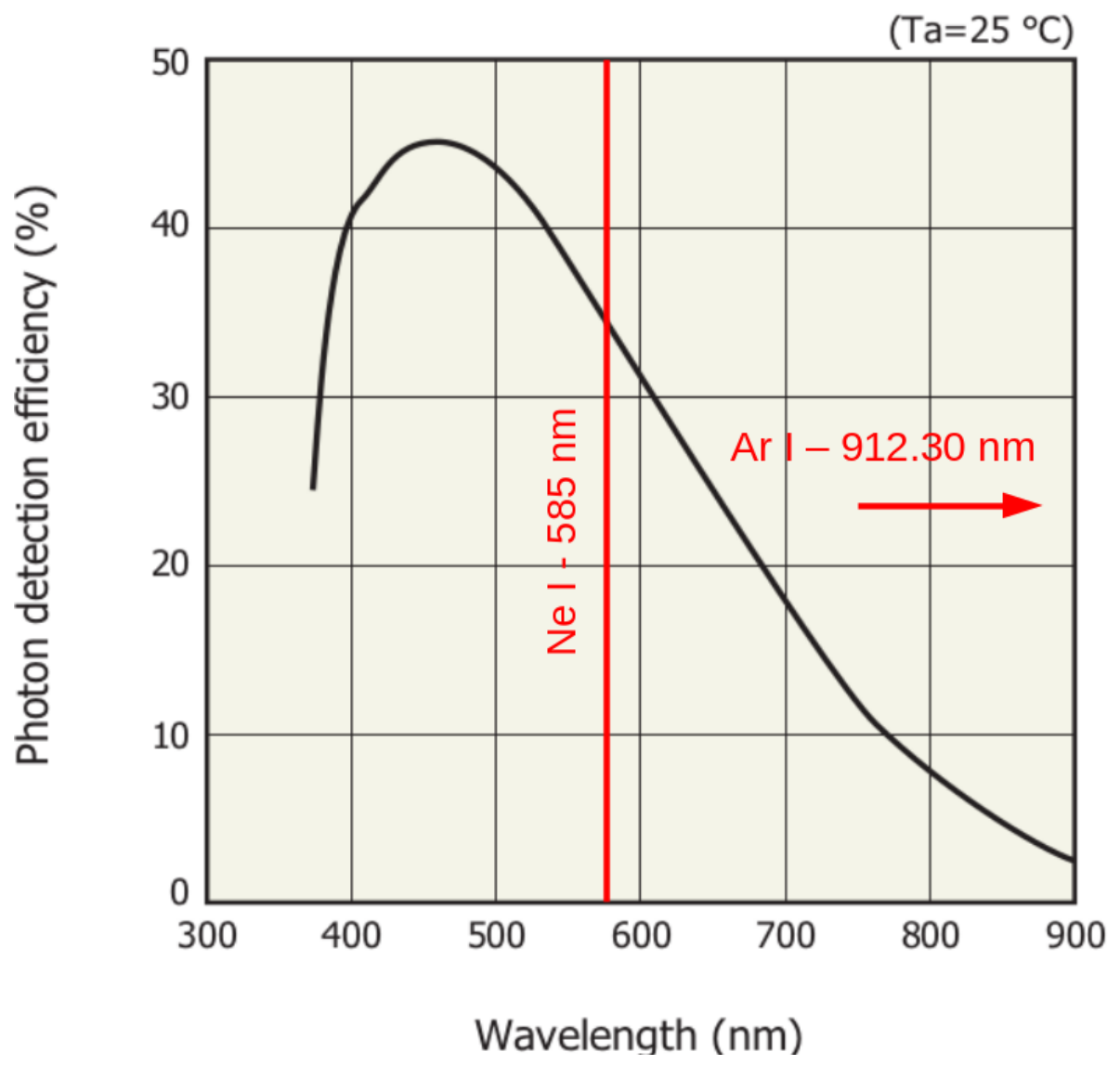

Figure 4: Ratio of detected-to-impacting photons on the APD. Better detection efficiency with neutral neon (Ne I). The APD detection efficiency was significantly improved from $2 \%$ at $912 \mathrm{~nm}$ with argon to $32 \%$ at $585 \mathrm{~nm}$ generated with neon. 
To ensure light being produced in CANOE by heavy-ion interactions in a rare gas, several irradiations were performed with various configurations shown in Table 3. It came out that the boron-neon configuration is optimal as expected by the energy deposition of alpha-particles and lithium ions in the buffer gas under neutron irradiation. Indeed, when CANOE was filled with high purity neon at 2 atm, opening the neutron beam shutter noticeably increased the count rate from 25 to 1217 cps with APD. Configurations 3 and 5 clearly shows that the neutron-induced heavy ions contribute quite totally to the optical signal. Even though less significant, the count rate of the uranium-neon configuration was twofold larger under neutron irradiation. Regarding the SiPM sensor, Table 4 shows that even if the dark noise is rather high with $65 \mathrm{E} 3 \mathrm{cps}$ because of the temperature of the detector, the count rate was doubled during irradiation. Neutron signal-to-dark-noise ratio is only dependent of the temperature at constant flux and cooling the SIPM at $-25{ }^{\circ} \mathrm{C}$ would decrease dark noise to $3 \mathrm{E} 3 \mathrm{cps}$ while the neutron signal would remain as high as 110E3 cps, increasing signal-to-noise ratio.

The APD signal variation when opening and closing the beam shutter was also recorded with an Agilent Technologies MSA9104A oscilloscope featuring a maximum sampling rate of $1 \mathrm{GHz}$. Due to memory limitation, a recording time window of $4 \mathrm{~s}$ was achievable to carry out such a test. A sampling rate of $125 \mathrm{MHz}$ was sufficient. Figure 5 shows the experimental output: one can clearly notice the neutron beam shutter maintained open for $1.8 \mathrm{~s}$.

High-purity uranium fission fragments as source of heavy-ions displayed a similar trend, even if the overall signal strength was reduced compared to the tubularboron excitation source due to smaller sensitive surface.

Finally, the low neutron fluence endured by the optical fibers induced negligible darkening effects: no difference in signal strength were observed between measurements over 3 days. 


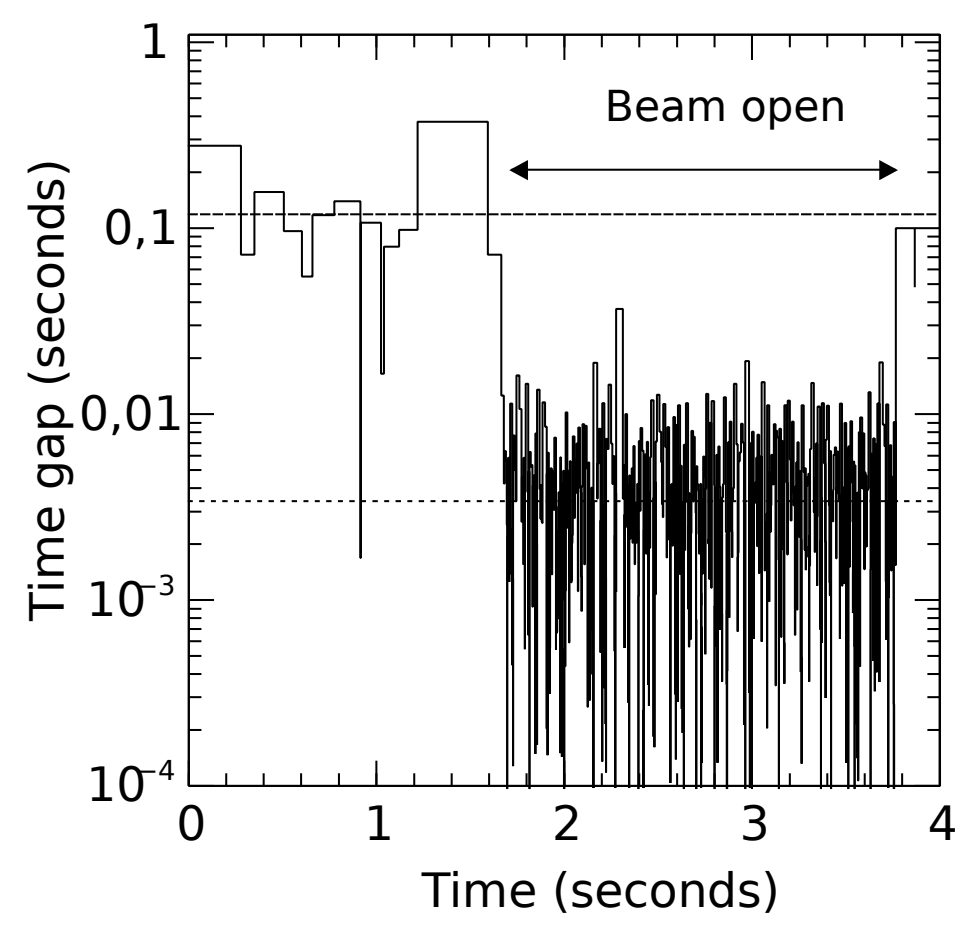

Figure 5: Change in the time gap between logical pulses generated by the APD photon counting module. One can note that the larger the time gap is, the lower the counting rate is. The Geiger-mode APD was coupled to the CANOE mock-up comprising a boron-coated cylinder and $2 \mathrm{~atm}$ neon filling gas. The dashed line stands for the average time gap when the beam shutter is closed, whereas the dotted one does for the time gap average when the shutter is open leading to neutron irradiation. 


\begin{tabular}{cccc}
\hline Configuration & Condition & Neutrons & Signal (cps) \\
\hline 1 & Boron-air & No & 25 \\
2 & Boron-air & Yes & 102 \\
3 & Neon only & Yes & 58 \\
4 & Boron-neon & No & 25 \\
5 & Boron-neon & Yes & 1217 \\
6 & Uranium-neon & No & 19 \\
7 & Uranium-neon & Yes & 66 \\
\hline
\end{tabular}

Table 3: Count rates obtained with APD for various configurations. The sensor was a Hamamatsu C13001-01 cooled Geiger mode APD. Optical fiber made of PMMA and $980 \mu \mathrm{m}$ diameter was employed unfocused on the sensor and CANOE as well. Configurations 3 and 5 clearly shows that the neutron-induced heavy ions contribute quite totally to the optical signal.

\begin{tabular}{cc}
\hline Count rate (cps) at 1 PE (cps) & Neutrons \\
\hline $65 \mathrm{E} 3$ & No \\
$110 \mathrm{E} 3$ & Yes \\
\hline
\end{tabular}

Table 4: Count rates obtained on Ketek WB-1125 SiPM. Optical fibre made of PMMA and $980 \mu \mathrm{m}$ diameter was employed unfocused on both the light sensor and CANOE. The count rate of the case without neutrons is mostly accounted for by the dark noise effect that could have been significantly reduced by cooling the detector down to $-25^{\circ} \mathrm{C}$.

\section{Conclusion}

The present paper presented preliminary results of optical fission chambers tested at the ORPHEE facility. Two technologies of fast-recovery-time and highefficiency light detector were evaluated, namely a Geiger-mode cooled Avalanche Photodiode (APD) and Large-area Silicon Photomultiplier (SiPM). Signals from 
both sensors were strong enough to largely overtake dark counts and follow operation of a beam shutter of a neutron beamline featuring a weak flux.

Neon as filling gas of the CANOE optical ionization chamber appeared to be a valuable choice, given its high luminous output in both the visible and nearinfrared spectrum. About 1217 counts per seconds were recorded on a cooled APD under a $8 \mathrm{E} 8 \mathrm{n} / \mathrm{cm}^{2} / \mathrm{s}$ neutron flux, with a signal-to-noise ratio of 48 . Even though complementary tests will have to be carried out, the present irradiation showed that CANOE and its appropriate light sensing technology was a promising instrumentation for neutron flux monitoring.

Optimization of light collection has to be performed for future application by means of flexible silica light pipes and optical assembly feeding a cooled light sensor. One will also have to harden both the chamber components and optical fiber to stand the harsh environment of a sodium-cooled fast reactor.

\section{Acknowledgments}

The authors are very thankful to the ORPHEE staff and more particularly to A. Menelle, F. Gibert for their general support and valuable advices, making the experiment possible.

\section{References}

[1] P. Filliatre, C. Jammes, B. Geslot, Stopping power of fission fragments of Cf-252 in argon: A comparison between experiments and simulation with the SRIM code, Nucl. Instrum. Methods Phys. Res. A 618 (1-3) (2010) 294-297. doi:10.1016/j.nima.2010.02.270.

[2] C. Jammes, P. Filliatre, B. Geslot, T. Domenech, S. Normand, Assessment of the High Temperature Fission Chamber Technology for the French Fast Reactor Program, IEEE TRANSACTIONS ON NUCLEAR SCIENCE $59(4,2)(2012)$ 1351-1359, 2nd International Conference on Advancements in Nuclear Instrumentation, Measurement Methods and their Applications, Ghent, BELGIUM, JUN 06-09, 2011. doi:10.1109/TNS.2012.2205161. 
[3] C. Jammes, N. Chapoutier, P. Filliatre, J. P. Jeannot, F. Jadot, D. Verrier, A. C. Scholer, B. Bernardin, Neutron flux monitoring system of the French GEN-IV SFR: Assessment of diverse solutions for in-vessel detector installation, NUCLEAR ENGINEERING AND DESIGN 270 (2014) 273282. doi:10.1016/j.nucengdes.2013.12.057.

[4] Z. S. Elter, C. Jammes, I. Pazsit, L. Pal, P. Filliatre, Performance investigation of the pulse and Campbelling modes of a fission chamber using a Poisson pulse train simulation code, Nucl. Instrum. Methods Phys. Res. A 774 (2015) 60-67. doi:10.1016/j.nima.2014.11.065.

[5] G. Galli, H. Hamrita, C. Jammes, M. J. Kirkpatrick, E. Odic, P. Dessante, P. Molinie, B. Cantonnet, J. C. Nappe, Characterization and Localization of Partial-Discharge-Induced Pulses in Fission Chambers Designed for Sodium-Cooled Fast Reactors, IEEE Trans. Nucl. Sci. 65 (9, 1) (2018) 2412-2420. doi:10.1109/TNS.2018.2861566.

[6] M. Lamotte, G. De Izarra, C. Jammes, Heavy-ions induced scintillation experiments, J. Instrum. 14 (09) (2019) C09024.

[7] L. Koch, Étude de la fluorescence des gaz rares excités par des particules nucléaires. Utilisation pour la détection des rayonnements nucléaires., Ph.D. thesis, Université de Paris (1959).

[8] W. R. Bennett, Optical spectra excited in high pressure noble gases by alpha impact, Ann. Phys. 18 (2) (1962) $367-420$.

[9] A. A Abramov, V. V Gorbunov, S. P Melnikov, A. Kh Mukhamatullin, A. Pikulev, A. V Sinitsyn, A. A Sinyanskii, V. M Tsvetkov, Luminescence of nuclear-induced rare-gas plasmas in near infrared spectral range, Vol. 6263, 2005. doi:10.1117/12.677457.

[10] G. Cheymol, H. Long, J.-F. Villard, B. Brichard, High level gamma and neutron irradiation of silica optical fibers in CEA OSIRIS nuclear reactor, IEEE Trans. Nucl. Sci. 55 (4) (2008) 2252-2258. 
228 [11] M. Lamotte, G. de Izarra, C. Jammes, Development and first use of an 229 experimental device for fission-induced spectrometry applied to neutron 230 $\quad$ flux monitoring, Nucl. Instrum. Methods Phys. Res. A (2019) 163236.

${ }_{231}^{2}$ [12] V. Méot, O. Roig, B. Rossé, P. Morel, J.-M. Daugas, D. Doré, ${ }_{232}$ A. Letourneau, A. Menelle, Direct measurement of the inelastic neutron ${ }_{233}$ acceleration by $177 \mathrm{mlu}$, in: EPJ Web Conf., Vol. 2, EDP Sciences, 2010, $234 \quad$ p. 05004 .

[13] E. Simon, P. Guimbal, Performance assessment of imaging plates for the 236 JHR transfer Neutron Imaging System, in: EPJ Web Conf., Vol. 170, EDP ${ }_{237} \quad$ Sciences, 2018, p. 04021. 